\title{
Familiality and Partitioning the Variability of Femoral Bone Mineral Density in Women of Child-Bearing Age
}

\author{
MaryFran R. Sowers, ${ }^{1}$ Michael Boehnke, ${ }^{2}$ Mary L. Jannausch, ${ }^{1}$ Mary Crutchfield, ${ }^{1}$ Genie Corton, ${ }^{1}$ and \\ Trudy L. Burns ${ }^{3}$ \\ Departments of ${ }^{1}$ Epidemiology School of Public Health and ${ }^{2}$ Biostatistics, 109 S. Observatory St., University of Michigan, Ann Arbor, \\ Michigan 48109; and ${ }^{3}$ Department of Preventive Medicine and Environmental Health, University of Iowa, Iowa City, Iowa 52242, USA
}

Received November 2, 1990, and in revised form March 6, 1991

Summary. The contributions of polygenic loci and environmental factors to femoral bone mineral density (BMD in $\mathrm{g} / \mathrm{cm}^{2}$ ) variability were estimated in modified family sets consisting of women of child-bearing age. Femoral BMDs were measured in 535 women who were members of 137 family sets consisting minimally of an index, her sister, and unrelated female control. The family set could also include multiple sisters and first cousins. Women included in these family sets were all between 20 and 40 years of age to minimize the cohort effects of maturation and menopause on measures of BMD. BMDs were measured at three femoral sites using dual photon densitometry. Values were regressed on age and Quetelet Index which explained 13-15\% of the variability in BMD (dependent on site). Subsequent variance components analysis on the residuals indicated that unmeasured polygenic loci accounted for substantial additional variability: $67 \%$ for femoral neck, $58 \%$ for Wards triangle, and $45 \%$ for trochanter. These results suggest that polygenic loci account for approximately half of the variability in maximal femoral BMD.

Key words: Bones - Bone mineral density - Osteoporosis Genetic - Epidemiologic methods.

Study of factors associated with bone mineral density (BMD in $\mathrm{g} / \mathrm{cm}^{2}$ ) is important to establish profiles of individuals who are at risk for osteoporosis and fracture [1]. Osteoporosis is thought to be multifactorial in its etiology, involving both heredity and environmental contributions [2, 3].

Increasingly, researchers hypothesize that a primary determinant of risk for osteoporosis may be the amount of skeletal bone mass acquired in adolescence and early adulthood [4], which is referred to as "peak" or "maximal" bone mass. A lower peak bone mass, premenopausally, when combined with a substantial bone loss, perimenopausally, may place women at a higher risk of osteoporosis. Frequently, the genetic contribution to osteoporosis has been based on the study of bone in aged individuals $[5,6]$, mixed generation groups [7-10], and mixed gender groups [5,11]. However, in women the protracted events of menopause and associated estrogen replacement may obscure the nature and strength of the genetic contribution. Furthermore, maximal BMD in early adulthood may have different genetic determinants than postmenopausal osteoporosis. Postmenopausal

Offprint requests to: MaryFran R. Sowers bone loss may be influenced by genetic factors associated with the level of hormones, perimenopausally, as well as by the environmental influences of exposure to exogenous estrogen.

Estimates of heritability may also vary according to particular bone site, potentially because of the nature of the interaction of genetic and environmental influences. For example, Dequeker et al. [12] reported a heritability estimate of 0.75 for the distal radius among 13 pairs of monozygotic and dizygotic twins (greater than 25 years of age) whereas the estimate of heritability at the spine among the same twin pairs was $\mathbf{- 0 . 5 7}$. Though hip fracture has substantially greater social, economic, and mortal outcomes than fracture of spine or wrist, relatively few studies have reported a genetic component for BMD of the femur [3], suggesting the need to determine consistency of heritability at multiple bone sites.

The purpose of this study was to estimate for peak femoral bone mass the proportion of variability explained by genetic and environmental factors in a sample of 535 healthy women, aged $20-40$ years. The results provide insight into the contribution made by familial factors to the variability of peak femoral BMD.

\section{Materials and Methods}

\section{Source Population}

This study was designed to describe characteristics of maximal bone mass, including its familiality, in adult women, ages $20-40$ years. A modified family set method was used to identify related and nonrelated participants for study of characteristics that might be familial. To that end, we recruited groups that consisted minimally of an index woman, her sister, and a nonrelated friend control identified by the index, within the specified age range. Female, age-eligible first cousins and all age-eligible sisters of the index were asked to participate, if available. As ascertainment was independent of femoral bone mass, assignment as an index case among sisters was random and based only on which sister was located by telephone first.

Participants were associated with Tecumseh, Michigan, a rural community $(n \sim 10,000)$ and its immediate environs which have served as the location for the Tecumseh Community Health Study (TCHS), a total-community study of chronic diseases. Families with age-eligible female siblings were identified from the TCHS baseline family member roster. Additional participants were recruited by presenting the study to organizations and employers with substantial female membership, and advertising in the local newspaper.

Women were excluded from data collection if they were not $20-40$ years, were pregnant or thought they might be pregnant, or were cognitively unable to provide informed consent. Women who identified their ethnic origin as non-Caucasian were eliminated from 
data analyses because of small numbers. A total sample of 535 women in 137 family sets contributed BMD information. There were one hundred forty-five unrelated controls, 60 cousins, and 137 sibships distributed as 96 sibships with 2 sisters, 31 sibships with 3 sisters, 7 sibships with 4 sisters, 2 sibships with 5 sisters, and 1 sibship with 7 sisters. Our participation rate was $81 \%$ of women contacted who lived within 25 miles of Tecumseh. All activities were undertaken according to guidelines of the University of Michigan Institutional Review Board.

\section{Measurements}

Women were contacted by an interviewer to describe the study protocol and to secure consent to participate. A clinic visit was scheduled and a self-administered health questionnaire was provided. The clinic visit included an additional interview about lifestyle, diet, reproductive history, and health history. BMDs (bone mineral content/bone area) of the femoral neck, Wards triangle, and trochanter were measured using a Lunar DP3 ${ }^{\mathrm{TM}}$ dual photon densitometer (Madison, WI) fitted with a $\mathrm{Gd}^{153}$ source. The location of these specific sites has been previously described [13]. The coefficient of variation from repeated measures, a measure of precision, was $3 \%$. The source was replaced immediately prior to the beginning of this study and was not replaced during the 9-month period of data collection. Calibration was undertaken before each clinic visit; generally, 6-8 women were measured during each clinic visit. A single technician conducted all measurements.

The hip was selected for measurement because fracture at this site has substantially greater social, economic, and mortal outcomes than fracture of the spine or wrist [14]. Measurement of BMD has been reported to be predictive of hip fracture incidence and also reflects spinal osteopenia $[15,16]$.

The clinical assessment included measurement of height and weight. Height was measured to the nearest millimeter using a height board; weight was measured in quarter pounds using a standardized balance-beam scale. These values were used to calculate a Quetelet Index (weight $/$ height $^{2}$ ) which is weight adjusted for height.

\section{Variables and Statistical Analyses}

All variables were assessed for the normality of the distribution, and descriptive statistics were calculated. Prior to analyses to characterize potential genetic or familial associations, we examined factors that might influence BMD. This examination used only data from the 282 women who were neither related by blood nor residence in the same household. Factors examined included current and historic calcium intake, smoking practices, alcohol use, reproductive characteristics (i.e., parity, age of menarche, oral contraceptive use), and age and measures of body size. Age and Quetelet Index were significantly associated with femoral BMD, explaining between 15 and $19 \%$ of the variability in these unrelated participants, depending on the site [17]. BMD values were regressed on age and Quetelet Index; residual values were used in the analysis of variance and variance components analysis.

One-way analysis of variance was used to assess familiality of BMD variability [18]. Familiality describes the influence of family membership on a phenotypic characteristic, but does not reflect whether phenotypic expression is due to genetic factors, common living environment, or both.

Variance components analysis was used to estimate the proportion of variability of femoral BMD due to unmeasured genetic and environmental factors. Residuals from the regression analysis were analyzed under the polygenic model [19]. The model assumed that adjusted femoral BMD represented the summed effects of additive genes, unmeasured factors shared by members within the same family set, and unmeasured factors specific to each individual (including measurement error) to provide a mechanism other than shared genes as a possible explanation of the familial aggregation of femoral BMD. We speculated that unmeasured factors shared by members within the same family might include such things as eating patterns, frequency of pregnancy and lactation, and even medical careseeking.

Following Lange et al. [20, 21], we assumed that after adjustment
Table 1. Femoral bone mineral density $\left(\mathrm{g} / \mathrm{cm}^{2}\right)$ of 535 women contributing to 137 family sets, and the 282 members of the total sample who are not related by blood

\begin{tabular}{llllll}
\hline & \multicolumn{2}{l}{$\begin{array}{l}\text { Total sample } \\
(\mathrm{n}=535)\end{array}$} & & \multicolumn{2}{l}{$\begin{array}{l}\text { Unrelated women } \\
(\mathrm{n}=282)\end{array}$} \\
\cline { 2 - 3 } \cline { 5 - 6 } Sites $\left(\mathrm{g} / \mathrm{cm}^{2}\right)$ & Mean & SD & & Mean & SD \\
\hline Femoral neck & 0.95 & 0.12 & & 0.95 & 0.12 \\
Wards triangle & 0.88 & 0.14 & & 0.89 & 0.15 \\
Trochanter & 0.78 & 0.13 & & 0.79 & 0.14 \\
\hline
\end{tabular}

Table 2. Comparison of characteristics of 535 women in the total sample and the 282 members of the total sample who are not related by blood

\begin{tabular}{lrrrrr}
\hline & \multicolumn{2}{c}{ Total sample } & & \multicolumn{2}{c}{ Unrelated members } \\
\cline { 2 - 3 } \cline { 5 - 6 } Characteristic & Mean & SD & & Mean & SD \\
\hline Age (years) & 31.3 & 4.8 & & 31.9 & 5.1 \\
Height (cm) & 163.1 & 5.8 & & 163.3 & 5.7 \\
Weight (kg) & 66.4 & 14.6 & & 67.6 & 16.2 \\
$\begin{array}{l}\text { Quetelet Index } \\
\left(\mathrm{wt} / \mathrm{ht}^{2} \text { ) }\right.\end{array}$ & 24.9 & 5.3 & & 25.3 & 6.0 \\
\hline
\end{tabular}

for age and Quetelet Index, the femoral BMD measurements for a family set followed a multivariate normal distribution. Theoretic justification of the assumption of multivariate normality has been given elsewhere $[21,22]$. Under these assumptions, we partitioned the total within-in individual phenotypic variability $\sigma^{2}$ of adjusted femoral BMD as a sum of variance components $\sigma^{2}=\sigma g_{2}+\sigma c_{2}+$ $\sigma \mathrm{e}^{2}$, where $\sigma \mathrm{g}_{2}$ is the additive genetic variance, $\sigma \mathrm{c}_{2}$ is the variance of factors shared by members of the same family set, and $\sigma \mathrm{e}_{2}$ is the variance of factors specific to the individual, including measurement error. Under this model, covariances between relatives are $1 / 2 \sigma g_{2}+$ $\sigma c_{2}$ for sisters, $1 / 8 \sigma g_{2}+\sigma c_{2}$ for cousins, and $\sigma c_{2}$ for unrelated members of the same family set.

Under the assumption of independent family sets, the loglikelihood of the data set was the sum of the multivariate normal log-likelihoods for the individual family sets. Calculation and maximization of these log-likelihoods was carried out using the computer program FISHER [23]. Maximizing the log-likelihood permitted maximum likelihood parameter estimation; it also provided a means for hypothesis testing of nested models using the likelihood ratio criterion, and for maximum likelihood comparison of nonnested models. We constrained the variance components to be positive because there is no evidence of familial disaggregation in BMD.

\section{Results}

The mean and standard deviation of the normally distributed femoral BMDs for the neck, Wards triangle, and trochanter are shown in Table 1 . These values are slightly lower $(\sim 3 \%$ for femoral neck and Wards triangle; $2 \%$ for trochanter) than those reported by Mazess and Barden [24] who used the same instrumentation to characterize women of the same age group. Table 2 describes the physical characteristics of women in the sample including height, weight, Quetelet Index, and age.

A one-way analysis of variance of the unadjusted femoral BMD values suggested highly significant familial aggregation and were as follows: femoral neck $\left(\mathrm{R}^{2}=0.65, P<0.0001\right)$ Wards triangle $\left(\mathrm{R}^{2}=0.64, P<0.0001\right)$; and trochanter $\left(\mathrm{R}^{2}\right.$ $=0.66, P<0.0001)$. The proportion of variation explained by sibships for values, adjusted for age and Quetelet Index, for femoral BMD were as follows: femoral neck $\left(\mathrm{R}^{2}=0.68\right.$, 
Table 3. Variance components estimates (with standard errors in parentheses) for bone mineral density of three locations of the femoral head, following adjustment for age and Quetelet Index, with likelihood ratio statistics $(-2 \log \Lambda)$ to compare possible models to the complete model

\begin{tabular}{|c|c|c|c|c|}
\hline Site & $\begin{array}{l}\text { Individual-specific } \\
\text { environment component }\end{array}$ & $\begin{array}{l}\text { Additive } \\
\text { genetic component }\end{array}$ & $\begin{array}{l}\text { Family set } \\
\text { environment component }\end{array}$ & $-2 \log \Lambda$ \\
\hline \multicolumn{5}{|c|}{ Femoral neck } \\
\hline Model 1 & $\begin{array}{c}0.01212 \\
(0.00074)\end{array}$ & & & 37.35 \\
\hline Model 2 & $\begin{array}{c}0.00259 \\
(0.00159)\end{array}$ & $\begin{array}{l}0.00974 \\
(0.00208)\end{array}$ & & 0.00 \\
\hline Model 3 & $\begin{array}{c}0.00788 \\
(0.00075)\end{array}$ & & $\begin{array}{c}0.00424 \\
(0.00086)\end{array}$ & 5.55 \\
\hline Model 4 & $\begin{array}{c}0.00259 \\
(0.00159)\end{array}$ & $\begin{array}{c}0.00974 \\
(0.00208)\end{array}$ & $\begin{array}{l}0.00000 \\
* * *\end{array}$ & 0.00 \\
\hline \multicolumn{5}{|l|}{ Trochanter } \\
\hline Model 1 & $\begin{array}{c}0.01410 \\
(0.00086)\end{array}$ & & & 31.90 \\
\hline Model 2 & $\begin{array}{c}0.00486 \\
(0.00147)\end{array}$ & $\begin{array}{c}0.00931 \\
(0.00182)\end{array}$ & & 0.00 \\
\hline Model 3 & $\begin{array}{c}0.00933 \\
(0.00089)\end{array}$ & & $\begin{array}{c}0.00482 \\
(0.00010)\end{array}$ & 1.70 \\
\hline Model 4 & $\begin{array}{c}0.00570 \\
(0.00159)\end{array}$ & $\begin{array}{c}0.00743 \\
(0.00208)\end{array}$ & $\begin{array}{c}0.00110 \\
(0.00320)\end{array}$ & 0.00 \\
\hline \multicolumn{5}{|c|}{ Wards triangle } \\
\hline Model 1 & $\begin{array}{c}0.01724 \\
(0.00106)\end{array}$ & & & 27.60 \\
\hline Model 2 & $\begin{array}{c}0.00571 \\
(0.00184)\end{array}$ & $\begin{array}{c}0.01157 \\
(0.00228)\end{array}$ & & 0.00 \\
\hline Model 3 & $\begin{array}{c}0.01140 \\
(0.00108)\end{array}$ & & $\begin{array}{c}0.00580 \\
(0.00121)\end{array}$ & 1.00 \\
\hline Model 4 & $\begin{array}{c}0.00571 \\
(0.00184)\end{array}$ & $\begin{array}{c}0.01157 \\
(0.00228)\end{array}$ & $\begin{array}{l}0.00000 \\
* * *\end{array}$ & 0.00 \\
\hline
\end{tabular}

*** Parameter bounded at zero

$P<0.0001)$; Wards triangle $\left(\mathrm{R}^{2}=0.67, P<0.0001\right)$; and trochanter $\left(\mathrm{R}^{2}=0.69, P<0.0001\right)$.

Variance components analysis was used to characterize the summed effects of unmeasured genes and unmeasured environmental factors in addition to that already attributed to body size, expressed as Quetelet Index and age. Residuals from regression analysis of BMD with age and Quetelet Index were used under the assumption that age and Quetelet Index were known concomitants and that adjustment for them allowed for the description of polygenic factors for BMD in excess of body size. Results of the analysis for the age and Quetelet-adjusted femoral BMDs, including the parameter estimates and their standard errors, are shown in Table 3. The variance shown for Model 1 is segmented into separate components in Models 2, 3, and 4. Model 4 is the complete model reflecting the sum of the variance components for which partitioning was undertaken. The likelihood ratio statistics compare individual component models to the complete model to test the hypothesis of no difference between models.

The estimates shown in Table 3 suggest the presence of a significant genetic effect for all three sites, although shared environment cannot be dismissed as an explanation for trochanter and Wards triangle. At the femoral neck site, the most parsimonious model included genes and the unmeasured component specific to the individual. This model attributed $79 \%$ of the variability in regressed BMD, adjusted for age and body size, to genes $(79 \%=0.00974 /(0.00259+$ $0.00974)$ ). For Wards triangle, this genetic model attributed $67 \%$ of the variability in adjusted BMD to genes. For the trochanter, the complete model attributed $52 \%$ of variability to genes and $7 \%$ of the variability to an unmeasured factor shared by members of a family set; the genetic model attributed $66 \%$ of the variability.
Table 4 summarizes the proportion of variability explained by measured concomitants, unmeasured genes, and unmeasured factors shared by members of a family set. At the femoral neck, age and body size, the measured concomitants, accounted for $15 \%$ of the variability in BMD, leaving $85 \%$ of variability unexplained. Under the variance components analysis, unmeasured genes accounted for an additional $67 \%(85 \% \times 79 \%)$ of the variability. Similarly, in models for the trochanter and Wards triangle, genes accounted for an additional $45 \%$ and $58 \%$ of variability, respectively. The three proximal femur sites are interrelated such that quantified variability associated with genes is not independent.

\section{Discussion}

This partitioning of the variability of peak femoral BMD suggests that substantial variation may be explained by unmeasured genes. Prior to considering familial factors, measured concomitants (age and Quetelet Index) explained 13-15\% of the variability. Unmeasured genes and unmeasured environmental factors shared by members of a family set explained an additional $51-67 \%$ of the variability in peak femoral BMD, depending on femoral site.

The values reported appear to be consistent with those of Pocock et al. [25] who studied femoral BMD in 32 female and 6 male monozygotic twin pairs, as well as 26 female and 1 male dizygotic twin pairs (aged 24-75 years). The genetic component would have been greater had we not already adjusted for the variability attributable to body size (data not shown), a characteristic previously observed to have a genetic component $[26,27]$.

Establishing that genes play a role in determining femoral 
Table 4. Sources of variability in peak femoral bone mineral densities assuming the complete model (Model 4)

\begin{tabular}{llc}
\hline Site & Component & $\begin{array}{l}\text { Percent } \\
\text { variability } \\
\text { explained }\end{array}$ \\
\hline Femoral neck & Age, Quetelet Index & 15 \\
& Unmeasured genes & 67 \\
& Unmeasured family set & \\
$\quad$ environment & 0 \\
Unexplained variance & 18 \\
Trochanter & Age, Quetelet Index & 14 \\
& Unmeasured genes & 45 \\
& Unmeasured family set & \\
& environment & 6 \\
Wards triangle & Unexplained variance & 35 \\
& Age, Quetelet Index & 13 \\
& Unmeasured genes & 58 \\
& Unmeasured family set & \\
& environment & 0 \\
& Unexplained variance & 29 \\
\hline
\end{tabular}

BMD in women of child-bearing age is an important step in characterizing genetic etiology of osteoporosis. Previous studies of the role of genetics in BMD have typically focused on samples of individuals who were aged $[5,6]$ or mixed generations $[7-10]$. The interpretation of a genetic contribution to peak BMD in these studies may have been obscured by the multiple lifestyle factors that influence the estimate of BMD. In women particularly, the protracted onset of menopause and treatment of its symptomatology may obscure important relationships [8]. However, studies of more aged populations may help to establish a role for an additional genetic contribution of menopause to BMD.

Previous evaluations of a genetic contribution to osteoporosis have used estimates of bone mineral content from the appendicular skeleton, usually the distal radius, in studies of twins [5, 6, 11, 12], mother/daughter pairs [8, 9, 28], and racial differences $[29,30]$. However, it is recognized that hip fractures are the predominant events of interest in terms of increased mortality and health care costs [14]. Fractures at the hip may be associated with lifestyle risks different than risks associated with the distal radius. For example, weight bearing is likely to contribute more strongly to the level of femoral BMD and influence the phenotypic expression of the heritable contribution. Thus, it is important to determine the consistency of heritable components at several skeletal sites. Recent studies using parent/offspring correlations $[10,31$, 32] and relatives of osteoporotic patients [33] suggest the importance of a genetic role in peak bone density. Because the studies are characterized by small samples of volunteers, confirmation with a larger sample using a community-based sampling frame is important.

Variance components analysis can be helpful in distinguishing whether the familiality of femoral BMD are more likely to have a genetic or environmental component. Even when such a distinction is made, the magnitude may not be definitive. Though the genetic model has a substantially greater likelihood than the shared family set environmental model for the femoral neck, the shared family environment model cannot be dismissed as an explanation for the data at the other two sites. This study suggests that consideration of genetic influence is important. Having established a substantial role for gene(s) in peak femoral bone mass, the next step would be to begin a more systematic study of genetic etiol- ogy. For example, no study has identified that healthy women with low peak BMD have a genetic profile different from that of women with average peak BMD; this is an area for future exploration. Additionally, we have shown that low estrogen levels are significantly associated with low premenopausal BMD [34]. It would be important to determine if bone mass heritability is similar in premenopausal women with higher and lower estrogen levels.

Acknowledgment. This work was supported by the Future Leader Award, International Life Science Institute Nutrition Foundation.

\section{References}

1. Anonymous (1984) Osteoporosis: consensus conference. JAMA 252:799-802

2. Pollitzer WS, Anderson JJB (1989) Ethnic and genetic differences in bone mass: a review with a hereditary vs environmental perspective. Am J Clin Nutr 50:1244-1259

3. Kelly PJ, Eisman JA, Sambrook PN (1990) Interaction of genetic and environmental influences on peak bone density. Osteoporosis Int 1:56-60

4. Newton-John HF, Morgan DB (1968) Osteoporosis: disease of senescence? Lancet 1:232-233

5. Moller M, Horsman A, Harvald B, Hauge M, Henningsen $\mathrm{K}$, Nordin BEC (1978) Metacarpal morphometry in monozygotic and dizygotic elderly twins. Calcif Tissue Res 25:197-201

6. Christian JC, Yu P-L, Slemenda CW, Johnston CC Jr (1989) Heritability of bone mass: a longitudinal study in aging male twins. Am J Hum Genet 44:429-433

7. Garn SM (1963) Human biology and research in body composition. Ann NY Acad Sci 110:429-446

8. Sowers MFR, Burns TL, Wallace RB (1986) Familial resemblances of bone mass in adult women. Genet Epidemiol 3:85-93

9. Lutz J (1986) Bone mineral, serum calcium, and dietary intakes of mother/daughter pairs. Am J Clin Nutr 44:99-106

10. Seeman E, Hopper JL, Bach LA, Cooper ME, Parkinson E, McKay J, Jerums G (1989) Reduced bone mass in daughters of women with osteoporosis. N Engl J Med 320:554-558

11. Smith DM, Nance WE, Kang KW, Christian JC, Johnston CC $\mathrm{Jr}$ (1973) Genetic factors in determining bone mass. J Clin Invest 42:2800-2809

12. Dequeker J, Nijs J, Verstraeten A, Guesens P, Gevers G (1987) Genetic determinants of bone mineral content at the spine and radius: a twin study. Bone 8:207-209

13. Mazess RB, Barden H, Ettinger M, Schultz E (1988) Bone density of the radius, spine, and proximal femur in osteoporosis. $\mathbf{J}$ Bone Miner Res 3:13-18

14. Cummings SR, Kelsey JL, Nevit MC, O'Dowd KJ (1985) Epidemiology of osteoporosis and osteoporotic fractures. Epidemiol Rev 7:178-208

15. Hui SL, Slemenda CW, Johnston CC (1989) Baseline measurement of bone mass predicts fracture in white women. Ann Intern Med 111:355-361

16. Cummings SR, Black DM, Nevitt MC, Browner WS, Cauley JA, Genant HK, Mascioli SR, Scott DG, Steiger P (1990) Appendicular bone density and age predict hip fracture in women. JAMA 263:665-668

17. Sowers MFR, Kshirsagar A, Crutchfield M, Updike S (1991) Body composition, age and femoral bone mass of young women. Ann Epidemiol 1:245-254

18. Donner A (1986) A review of inference procedures for the intraclass correlation coefficient in the one-way random effects model. Int Stat Rev 54:67-82

19. Fisher RA (1918) The correlation between relatives on the supposition of Mendelian inheritance. Trans Roy Soc Edinburgh 52:399-433

20. Lange K, Westlake J, Spence MA (1976) Extensions to pedigree analysis. III. Variance components by the scoring method. Ann Hum Genet 39:485-491 
21. Lange K, Boehnke M (1983) Extensions to pedigree analysis. IV. Covariance components models for multivariate traits. Am J Med Genet 14:513-524

22. Lange K (1978) Central limit theorems for pedigrees. J Math Biol 6:59-68

23. Lange K, Weeks D, Boehnke M (1988) Programs for pedigree analysis. MENDEL, FISHER and dGENE. Genet Epidemiol $5: 471-472$

24. Mazess RB, Barden HS (1991) Bone density in premenopausal women: effects of age, dietary intake, physical activity, smoking, and birth-control pills. Am J Clin Nutr 53:132-142

25. Pocock NA, Eisman JA, Hopper JL, Yeates MG, Sambrook PN, Ebert S (1987) Genetic determinants of bone mass in adults: a twin study. J Clin Invest 80:706-710

26. Annest JL, Sing CF, Biron P, Mongeau JG (1979) Familial aggregation of blood pressure and weight in adoptive families. II. Estimation of the relative contributions of genetic and common environmental factors to blood pressure correlations between family members. Am J Epidemiol 110:492-503

27. Annest JL, Sing CF, Biron P, Mongeau JG (1983) Familial aggregation of blood pressure and weight in adoptive families. III Analysis of the role of shared genes and shared household environment in explaining family resemblance for height, weight and selected weight/height indices. Am J Epidemiol 117:492-506
28. Tylavsky FA, Bortz AD, Hancock RL, Anderson JJ (1989) Familial resemblance of radial bone mass between premenopausal mothers and their college-age daughters. Calcif Tissue Int 45:265-272

29. Trotter M, Hixon BB (1974) Sequential changes in weight, density, and percentage ash weight of human skeletons from an early fetal period through old age. Anat Rec 179:1-18

30. Leil Y, Edwards J, Shary J, Spicer KM, Gordon L, Bell NH (1988) The effects of race and body habitus on bone mineral density of the radius, hip, and spine in premenopausal women. $\mathrm{J}$ Clin Endocrinol Metab 66:1247-1250

31. Lutz J, Tesar R (1990) Mother-daughter pairs: spinal and femoral bone densities and dietary intakes. Am J Clin Nutr 52:872877

32. Matkovic V, Fontana D, Tominac C, Goel P, Chestnut JH III (1990) Factors that influence peak bone mass formation: a study of calcium balance and the inheritance of bone mass in adolescent females. Am J Clin Nutr 52:878-888

33. Evans RA, Marel GM, Lancaster EK, Kos S, Evans M, Wong SYP (1988) Bone mass is low in relatives of osteoporotic patients. Ann Intern Med 109:870-873

34. Sowers MFR, Shapiro B, Galbraith M, Jannausch M (1990) Health and hormonal characteristics of premenopausal women with lower bone mass. Calcif Tissue Int 47:130-135 